\title{
ИССЛЕДОВАНИЕ БИОЛОГИЧЕСКОЙ АКТИВНОСТИ ДРОЖЖЕЙ SACCHAROMYCES CEREVISIAE ФОTOMЕTРИЧЕСКИМ МЕТОДОМ
}

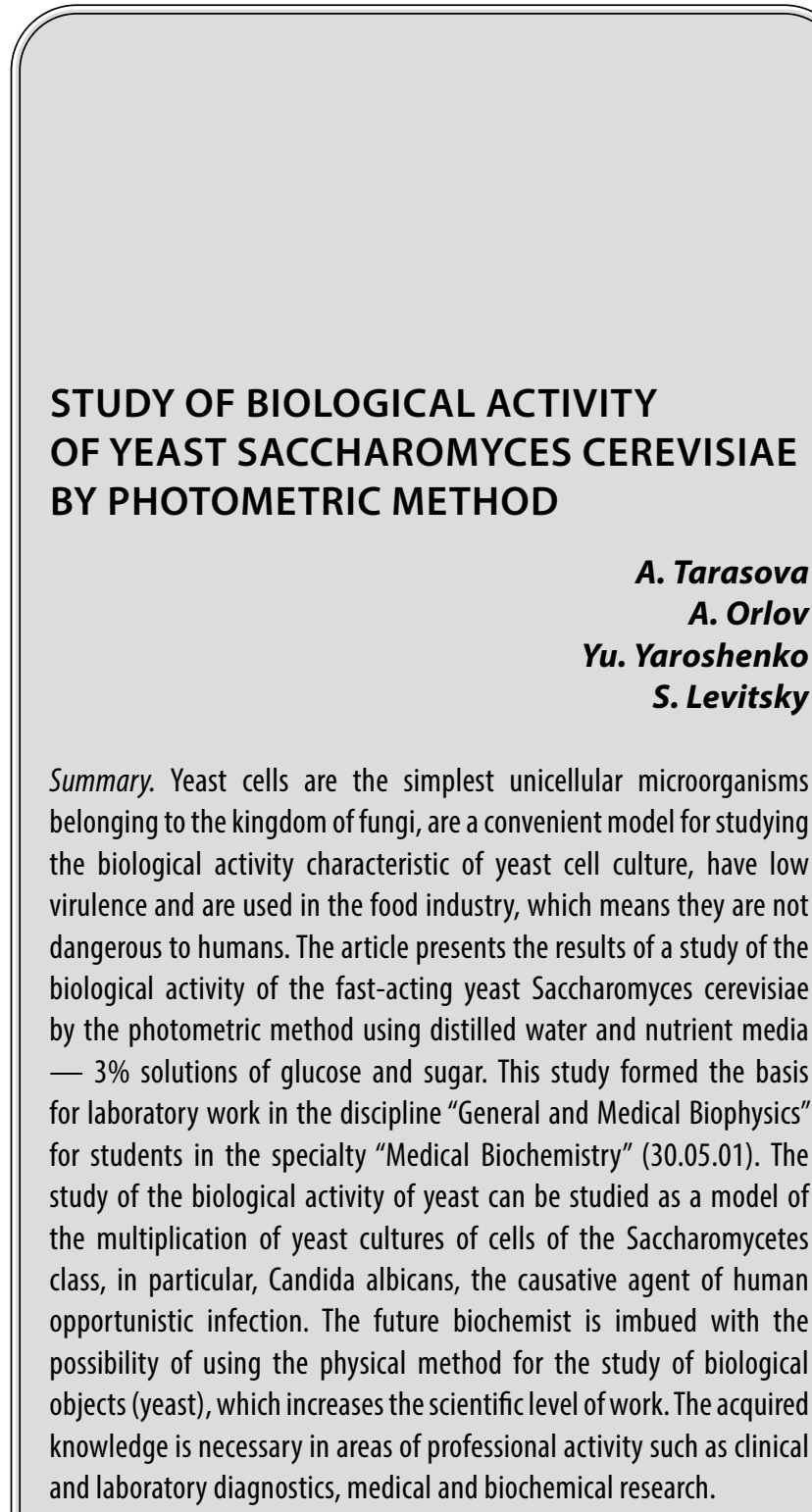

Keywords: biological activity, yeast Saccharomyces cerevisiae, Candida albicans, photometric method.
Тарасова Анна Владимировна К.п.н., дочент, ФГБОУ ВО «Северный государственный медицинский университет Минздрава России» vesy6@mail.ru

Орлов Артём Евгеньевич ФГБОУ ВО «Северный государственный медицинский университет Минздрава России»

Ярошенко Юлия Анатольевна Преподаватель, ФГБОУ ВО «Северный государственный медицинский университет

Минздрава России»

Левицкий Сергей Николаевич К.б.н., дочент, ФГБОУ ВО «Северный государственный медицинский университет Минздрава России»

Аннотация. Дрожжевые клетки - это простейшие одноклеточные микроорганизмы, принадлежащие к царству грибов, являются удобной моделью для изучения биологической активности, характерной для дрожжевой культуры клеток, обладают низкой вирулентностью и используются В пищевой отрасли, а значит, не являются опасными для человека. В статье представляются результаты исследования биологической активности быстродействующих дрожжей Saccharomyces cerevisiae фотометрическим методом с использованием дистиллированной воды и питательных сред - 3\%-ых растворов глюкозы и сахара. Данное исследование легло в основу лабораторной работы по дисциплине «0бщая и медицинская биофизика» для обучающихся по специальности «Медицинская биохимия» (30.05.01). Исследование биологической активности дрожжей возможно изучать как модель размножения дрожжевых культур клеток класса Сахаромицеты (Saccharomycetes), в частности, Candida albicans - возбудителя оппортунистической инфекции человека. Будущий врач-биохимик проникается возможностью применения физического метода для исследования биологических объектов (дрожжей), что повышает научный уровень работы. Полученные знания необходимы в сферах профессиональной деятельности таких, как клиническая и лабораторная диагностики, медицинские и биохимические исследования.

Ключевые слова: биологическая активность, дрожжи Saccharomyces cerevisiae, Candida albicans, фотометрический метод. 


\section{Ввемение}

B ыпускники специальности «Медицинская биохимия» (30.05.01) должны быть готовы к решению профессиональных задач, в частности, в сферах профессиональной деятельности таких, как клиническая и лабораторная диагностики, научные, медицинские и биохимические исследования. Приобретаемые знания и умения направлены на поддержание и сохранение здоровья человека, обеспечения профилактических мер, диагностических методов и терапии заболеваний [1, с. 5-6]. Поэтому у будущих врачей-биохимиков необходимо сформировать фундаментальные и прикладные естественнонаучные знания. При изучении дисциплины «Общая и медицинская биофизика» у обучающихся есть возможность использовать физические законы и методы для исследования биологических объектов. В статье рассмотрена возможность применения фотометрического метода для исследования биологической активности биологического объекта дрожжей Saccharomyces cerevisiae.

\section{Цель исследования}

Вклад дрожжей в развитие биологических, биохимических, биофизических наук огромен. На дрожжевых объектах проведены первые исследования по радиобиологии, генетические открытия (цитоплазматическая наследственность и расшифровка всего генома эукариотической клетки), физические параметры (температура, электромагнитные колебания) $[2,3,4]$.

Актуальность данного исследования заключается в том, что хлебопекарные дрожжи - удобная модель для изучения биологической активности характерной для дрожжевой культуры клеток. Исследуемые дрожжи принадлежат к краю Ascomicota, классу Hemiascomicete, отряду Saccharomicetales. К этому же классу относятся дрожжи Candida, а значит, они имеют сходные условия и закономерности размножения. Но хлебопекарные дрожжи Saccharomyces cerevisiae обладают низкой вирулентностью и используется в пищевой отрасли и не являются опасными для человека. Заметим, что вирулентность - это степень способности инфекционного агента вызывать заболевание организма или его гибель [5]. Вирулентность является мерой патогенности данного штамма вируса или микроорганизма.

Saccharomyces cerevisiae - это эукариотические клетки, модельные организмы, так как легко выращиваются, имеют низкую патогенность для человека и являются хорошо изученными. При сравнении клеток дрожжей Saccharomyces cerevisiae с бактериями, например, с кишечной палочкой Escherichia coli, отметим, что дрожжевые клетки имеет более сложную органи- зацию и содержат в несколько раз больше ДНК. Клетки Saccharomyces cerevisiae достаточно жизнеспособны, что имеет важное значение в генной инженерии [6].

Дрожжи рода Candida albicans входят в состав нормальной микрофлоры толстой кишки, рта и влагалища большинства здоровых людей, не вызывая заболеваний [6]. Патологические процессы у человека обусловлены размножением патогенных штаммов гриба и попаданием их в большом количестве в организм, а не просто наличием грибов Candida. Заболевание кандидоз (или молочница) возникает при снижении иммунитета, как общего, так и местного, поражает кровь и половые органы.

Систематические грибковые инфекции являются важными причинами заболевания и смертности пациентов с иммунодефицитом, например, в результате СПИДа, химиотерапии рака или трансплантации органов.

Дрожжи Candida albicans могут начать бесконтрольно размножаться под действием определенных факторов, таким образом вызывая появление самых разных негативных последствий. К данным факторам относятся продукты питания, которые способные усугубить течение болезни. Необходимо постараться исключить их из рациона человека.

Продукты питания, которые имеют высокий гликемический индекс, способны существенно увеличить уровень глюкозы в крови человека. При любых воспалительных процессах у человека их не рекомендуют употреблять в пищу. К таким продуктам относятся все сладости, создающие питательную среду для размножения, в том числе и грибов. Благодаря сладостям грибы растут, размножаются, нарушая баланс микрофлоры и ухудшая состояние здоровья человека. Поэтому не рекомендуется употребление в пищу человека большого количества конфет, пирожных и мороженого [7].

Традиционно соки и газированные напитки не относят к сладостям, но сахара в них присутствует не меньше, чем в конфетах. Известно, что в одном стакане кока-колы содержится восемь чайных ложек сахара. В натуральных и пакетированных соках, кроме глюкозы имеется и фруктоза, которая также быстро всасывается в кровь. При регулярном употреблении соков возможно обострение симптомов кандидоза в зависимости от того, где локализован патологический процесс. Поэтому газированные напитки и пакетированные соки следует минимизировать в рационе человека или лучше отказаться от них совсем. Из натуральных соков необходимо исключить соки, приготовленные из сладких фруктов, например, груш, персиков, винограда, инжира, яблок сладких сортов. 
В рисе, пшенице, кукурузе, картофеле содержится большое количество крахмала. В зернах риса его концентрация доходит до 86\%, в пшенице и кукурузе количество крахмала - 72-75\%, а в картофеле его доля составляет 24\%. Крахмал, попавший в организм человека поддается гидролизу и превращается в глюкозу, которая является питательной средой для размножения дрожжей Candida albicans [7, с. 319].

Соленые и копченые продукты питания содержат рафинированные углеводы, которыми питаются дрожжеподобные грибки. В пищевой промышленности при приготовлении маринадов, соусов, майонезов, кетчупов и соленых продуктов производители кладут большое количество сахара, что способствует увеличению скорости размножения грибов. Заметим, что алкогольные напитки также содержат сахар.

На кафедре медицинской и биологической физики Северного государственного медицинского университета (г. Архангельск) с помощью фотоэлектрического фотометра КФК-3-01 было проведено исследование биологической активности дрожжей Saccharomyces cerevisiae, целью которого было, используя теоретические знания из биологии и физики, установить зависимость прироста биомассы дрожжей, используемых при выпечке, от времени. В работе использовались растворы дрожжей в дистиллированной воде и в питательных средах. Питательными растворами являлись 3\%-ные растворы глюкозы (моносахарида) и пищевого сахара - сахарозы (дисахарида: остатков глюкозы и фруктозы). В исследовании была возможность оценить и сравнить влияние питательной среды на рост биомассы биологического объекта. Отметим, что под биологической активностью понимается скорость размножения дрожжевых клеток.

\section{Материал и методы исслеАОвания}

Дрожжи - группа одноклеточных микроорганизмов, относятся к царству грибов. Дрожжи утратили мицелиальное строение, обитают в жидких и полужидких средах, имеющих большое количество органических веществ. Дрожжи являются эукариотами, это значит, что генетический материал у них находится в ядре клетки. Известны 1500 видов существующих дрожжей $[8$, с. 4].

Объектом исследования были выбраны дрожжи Saccharomyces cerevisiae, используемые при выпечке. Данные дрожжи имеют диаметр 5-10 мкм, относятся к классу сахаромицетов, широко используются в производстве хлебопекарной и алкогольной продукции, а также в научных исследованиях.
Дрожжевые клетки Saccharomyces cerevisiae размножаются при помощи почкования вегетативным способом. Изначально на материнской клетке появляется вырост, затем происходит митоз ядра, образуется клеточная стенка и клетки отделяются друг от друга. Так как на материнской клетке от почкования остается шрам, это позволяет определить возраст клетки Saccharomyces cerevisiae. Материнская клетка обычно может образовывать от 20 до 30 почек. Оптимальными условиями для выращивания клеток дрожжей являются температура $30{ }^{\circ} \mathrm{C}$ и содержание пептона и глюкозы в дрожжевом растворе [8, с. 77].

Фотометрический метод - количественный метод, основанный на поглощении электромагнитного излучения данной длины волны анализируемым веществом в растворе. Эта зависимость определяется из закона Бугера-Ламберта-Бера. При фотометрии проводят измерения в инфракрасной, видимой и ультрафиолетовой областях спектра. В фотометрическом методе сравнивают потоки излучения, прошедшего через кювету исследуемого раствора, с первоначальным потоком (или потоком эталонного раствора). В методе используются приборы - фотометры. Фотоколориметрией называется метод, в котором используется излучение видимого диапазона спектра [9, с. 28], а прибор называют фотоколориметр.

При работе с фотометром измеряются коэффициенты пропускания и оптические плотности исследуемых растворов, а так же скорости изменения оптической плотности с последующим определением концентрации веществ в рассматриваемых растворах. Приборы применяются в сельском хозяйстве, пищевой и химической промышленностях, а также в медицине.

Принцип действия фотометрического метода основан на сравнении потоков излучения $\Phi_{0}$ и $\Phi$, где $\Phi_{0^{-}}$ прошедший поток через контрольный раствор или растворитель («холостая проба»), по отношению к которому производится измерение, $\Phi$ - поток излучения, прошедший через исследуемый раствор. Фотоприемник преобразует потоки излучения $\Phi_{0}, \Phi$ в электрические сигналы.

Коэффициент пропускания - безразмерная физическая величина, равная отношению:

$$
\tau=\frac{\Phi}{\Phi_{0}} .
$$

Численно коэффициент пропускания выражается в долях или в процентах.

В ранее проведенных работах [10, с. 97] было показано, что аналогично фитохрому растений в дрожже- 


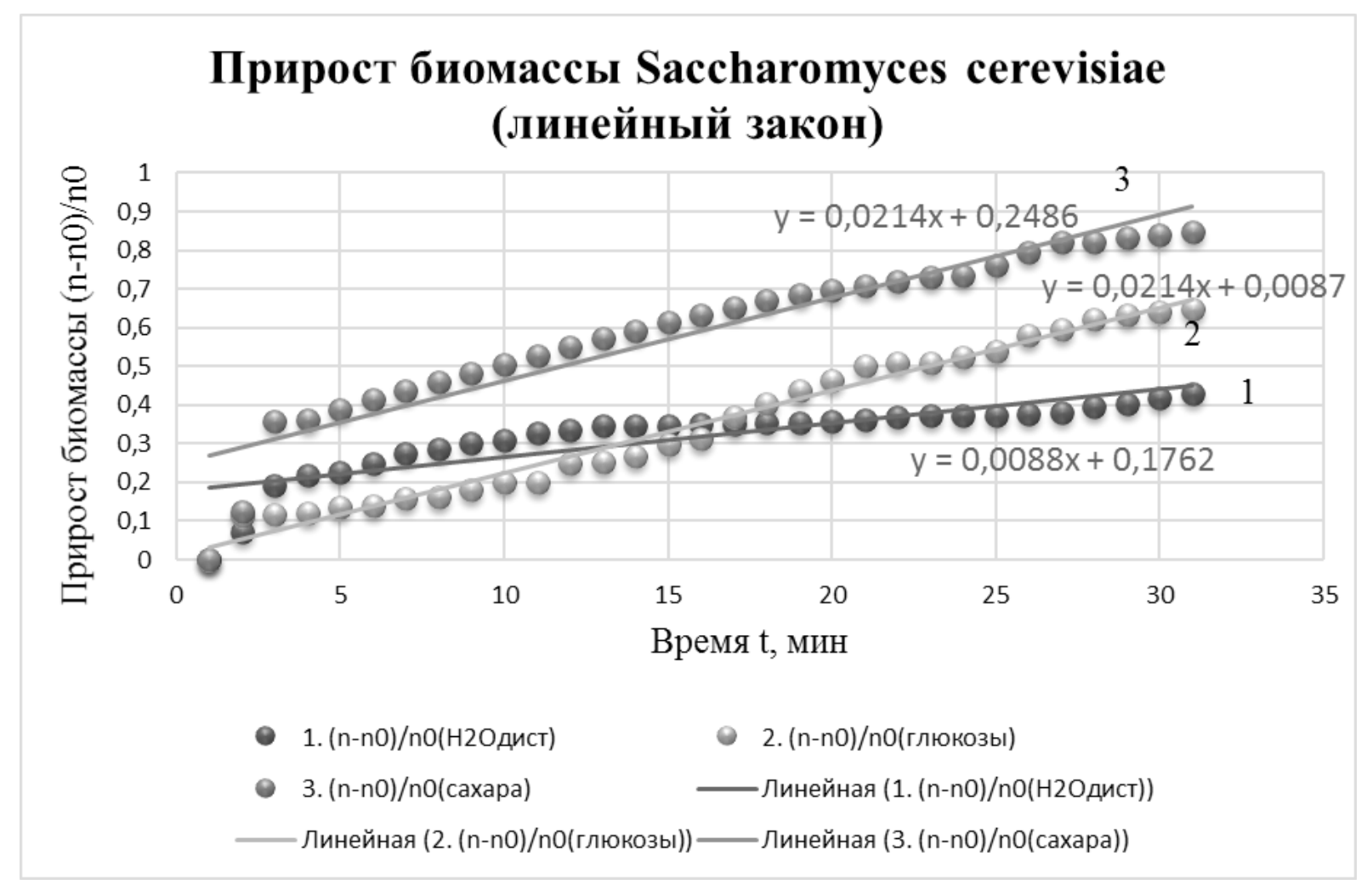

Рис. 1. Прирост биомассы дрожжей Saccharomyces cerevisiae (линейный закон)

вой клетке имеется фоторецептор, который называется хромопротеид, который наиболее чувствителен к излучению с длиной волны, соответствующей синему свету. При возбуждении хромопротеид нагревается, а теплота передается мембране, а затем всему организму. При этом усиливаются процессы деления клеток. Поэтому для исследования биологической активности дрожжей фотометрическим методом использовалась длина волны видимого спектра излучения: $\lambda=480$ нм, что соответствует синему цвету. Длина кюветы (толщина рабочего слоя) была подобрана в 1 см.

Эксперимент состоял из трёх серий. В первой - контрольным раствором являлась дистиллированная вода, а исследуемым раствором - дрожжи в дистиллированной воде. Во второй серии контрольный раствор - раствор глюкозы, а исследуемый - дрожжи в растворе глюкозы. В третьей серии эксперимента контрольный раствор раствор сахара, исследуемый - раствор сахара с дрожжами. В каждой серии эксперимента в исследуемый раствор добавлялось по четыре капли слабого раствора быстродействующих дрожжей, используемых при выпечке. Причем слабый раствор дрожжей готовился из расчёта 1 грамм на 200 мл дистиллированной воды. Измерения проводились каждую минуту в течение 30 минут при комнатной температуре $23-24^{\circ} \mathrm{C}$. Сначала эксперимент проводился с дистиллированной водой, затем с питательным раство- ром - 3\%-ным раствором глюкозы и - с 3\%-ным раствором сахара. Заметим, что подготовка к эксперименту (подбор длины кюветы, длины волны излучения, концентрация слабого раствора быстродействующих дрожжей) и пробные измерения проводились в течение трех месяцев.

Прирост биомассы живого вещества организма это количественное увеличение вещества организма, биоценоза или популяции. Обозначим первоначальную концентрацию дрожжей $n_{0}$, абсолютный прирост биомассы дрожжей $\Delta n$. Коэффициент пропускания раствора в начальный момент времени $-\tau_{0}$, а коэффициент пропускания в момент времени $t-\tau$. Относительный прирост биомассы дрожжей определяется:

$$
\frac{\Delta n}{n_{0}}=\frac{\tau_{0} \cdot \Phi_{0}-\tau \cdot \Phi_{0}}{\tau_{0} \cdot \Phi_{0}}=1-\frac{\tau}{\tau_{0}} .
$$

Подставляя разные значения $\tau-$ коэффициента пропускания в момент времени $t$, получали относительный прирост биомассы дрожжей в момент времени $t$.

\section{Результаты исслеАования и их обсу>}

В результате эксперимента была получена зависимость относительного прироста биомассы дрожжей от времени (рис. 1), построены линейные зависимо- 
сти прироста биомассы дрожжей в дистиллированной воде и в питательных растворах.

За время эксперимента больший прирост биомассы дрожжей Saccharomyces cerevisiae наблюдался в питательных растворах, чем в дистиллированной воде, причем выявилось очевидное влияние раствора сахара на размножение дрожжевых клеток.

Таким образом, у обучающихся в результате исследования есть возможность убедиться о влиянии питательного раствора на скорость размножения дрожжей Saccharomyces cerevisiae и перенести аналогичные закономерности на скорости размножения дрожжей Candida albicans. Кроме этого, студенты изучают физическую основу фотометрического метода и закономерности поглощения света веществом.

\section{Зак^ючение}

Данное исследование легло в основу лабораторной работы по дисциплине «Общая и медицинская биофизика» для обучающихся по специальности «Медицинская биохимия» (30.05.01). Лабораторная работа - это форма занятий в вузе, в ходе которой у обуча- ющихся есть возможность самостоятельно отработать навыки, необходимые для будущей практической деятельности в конкретной области профессиональной сферы. В содержании лабораторной работы учитывается профессионально направленный материал. Такая форма построения лабораторной работы обусловлена важностью учебного эксперимента и повышением мотивации к занятиям по Общей и медицинской биофизике.

Будущий Врач-биохимик проникается возможностью изучения физического метода (фотометрического метода) для исследования биологических объектов (дрожжей), что повышает научный уровень работы и позволяет демонстрировать значение и применение фундаментальных законов физики для нахождения решений в будущих профессиональных задачах, например, в клинико-лабораторной диагностике.

Исследование биологической активности дрожжей возможно изучать, как модель размножения дрожжевых культур клеток класса Сахаромицеты (Saccharomycetes), в частности, Candida albicans - возбудитель оппортунистической инфекции человека кандидоза (молочницы).

\section{ЛИТЕРАТУРА}

1. Приказ Министерства науки и высшего образования РФ от 13 августа 2020 г. N998 «06 утверждении федерального государственного образовательного стандарта высшего образования — специалитет по специальности 30.05.01 Медицинская биохимия» (с изменениями и дополнениями), 21с.

2. Вызулин С.А., Крыцын Д.И. Влияние температуры питательного раствора на биологическую активность дрожжей // Современное состояние и приоритеты развития фундаментальных наук в регионах. Труды III Всероссийской научной конференции молодых ученых и студентов. Краснодар: «Просвещение - юг», 2006. С. 136-137.

3. Ланец В.И. Дрожжи - удивительные одноклеточные грибы // Старт в науке. 2017. № 6 (часть 1). С. 13-21.

4. Hallen-Adams H.E., Suhr M.J. Fungi in the healthy human gastrointestinal tract (англ.) // Virulence. 1 November 2016. vol. 8. no. 3. P. 352-358.

5. Баснакьян И.А. Вирулентность // Большая российская энциклопедия. 2016. [Электронный ресурc]. URL: https://bigenc.ru/biology/text/1916109 (дата обращения: 13.10.2021).

6. Буряченко С.В. Молекулярная генетика дрожжей сахаромицетов Издательство: LAP LAMBERT Academic Publishing, 2016 г. [Электронный ресурс]. URL: https://docplayer.com/54118081-S-v-buryachenko-molekulyarnaya-genetika-drozhzhey-saharomicetov.html (дата обращения 12.10.2021)

7. Матюхина 3.П. Дрожжи // Товароведение пищевых продуктов. 6-е изд. М.: Академия, 2017. 336 c.

8. Меледина Т.В., Давыденко С.Г. Дрожжи Saccharomyces cerevisiae. Морфология, химический состав, метаболизм: Учеб. пособие. СПб.: Университет ИТМ0, 2015.88 C.

9. Ремизов А.Н. Медицинская и биологическая физика [Электронный ресурс]: учеб. для вузов/ А.Н. Ремизов. 4-е изд., испр. и перераб. Москва: ГЭ0TAP-Медиа, 2016. 656 c.: ил. URL: http://www.studentlibrary.ru/book/ISBN9785970435779.html (дата обращения: 08.10.2021).

10. Воскобойникова Е.А. Качество пива при использовании в технологии активации дрожжевых клеток синим цветом// Прикладные аспекты инноваций в биотехнологии: материалы II Всероссийской научно-практической конференции студентов и молодых ученых (14-16 июня 2018 года) / Алт. гос. техн. ун-т, БТИ. Бийск: Изд-во Алт. гос. тех. ун-та, 2019. 118 c. URL: http://www.bti.secna.ru/wp-content/uploads/2019/11/Prikladnye-aspekty-innovatsijv-biotehnologii-2018.pdf (дата обращения: 12.10.2021).

( ) Тарасова Анна Владимировна ( vesy6@mail.ru ), Орлов Артём Евгеньевич,

Ярошенко Юлия Анатольевна, Левицкий Сергей Николаевич.

Журнал «Современная наука: актуальные проблемы теории и практики» 